\title{
A new custom-made plate preparation method for bony mallet finger treatment and a comparison with extension block technique
}

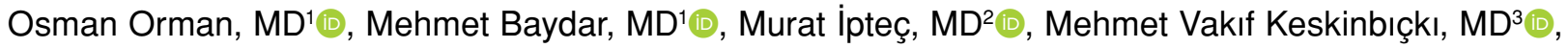 \\ Hüseyin Emre Akdeniz, MD'1D, Kahraman Öztürk, MD'1D \\ ${ }^{1}$ Hand Surgery, University of Health Sciences, Metin Sabancı Baltalimani Bone Diseases Training and Research Hospital, Istanbul, Turkey \\ ${ }^{2}$ Hand Surgery, Ministry of Health, Başakşehir City Hospital, Istanbul, Turkey \\ ${ }^{3}$ Hand Surgery, Ministry of Health, Dr. Ersin Arslan Training and Research Hospital, Gaziantep, Turkey
}

Mallet finger is an avulsion fracture of the distal phalanx or rupture of the extensor terminal band caused by distal interphalangeal (DIP) joint hyperflexion or axial loading. In the treatment of mallet finger fractures, surgical repair is recommended in cases where the fracture involves more than one-third of the distal phalanx joint surface or the distal phalanx becomes volar subluxated. ${ }^{[1-3]}$ Untreated or poorly treated mallet finger may result in extensor lag and swan neck deformity. ${ }^{[4,5]}$

Both percutaneous and open surgical methods are used in the treatment of mallet finger fractures. The extension block technique (EBT) ${ }^{[6-10]}$ hook plate technique $(\mathrm{HPT}){ }^{[3,11]}$ percutaneous screwing, ${ }^{[12]}$

Received: April 10, 2021

Accepted: May 27, 2021

Published online: November 19, 2021

Correspondence: Osman Orman, MD. İstanbul Metin Sabancı Baltalimanı Kemik Hastalıkları Eğitim ve Araştırma Hastanesi, El Cerrahisi Kliniği, 3447 Sarıyer, İstanbul, Türkiye.

E-mail: osmanorman@gmail.com

Doi: $10.52312 / j d r s .2021 .156$

Citation: Orman O, Baydar M, İpteç M, Keskinbıckı MV, Akdeniz $\mathrm{HE}$, Öztürk K. A new custom-made plate preparation method for bony mallet finger treatment and a comparison with extension block technique. Jt Dis Relat Surg 2021;32(3):617-624.

(02021 All right reserved by the Turkish Joint Diseases Foundation

This is an open access article under the terms of the Creative Commons Attribution-NonCommercial License, which permits use, distribution and reproduction in any medium, provided the original work is properly cited and is not used for commercial purposes (http://creativecommons.org/licenses/by-nc/4.0/).

\section{ABSTRACT}

Objectives: In this study, we aimed to describe a new hook plate technique (HPT) and to compare our results with the conventional extension block technique (EBT) with a Kirschner wire (K-wire) for bony mallet finger treatment.

Patients and methods: Between April 2015 and January 2018, a total of 19 patients including 10 who were treated with EBT ( 7 males, 3 females; mean age: $30.1 \pm 7.3$ years; range, 17 to 48 years) and nine who were treated with HPT (6 males, 3 females; mean age: $31.7 \pm 11.3$ years; range, 19 to 42 years) for bony mallet finger with distal interphalangeal (DIP) joint subluxation and/or fracture fragment larger than one-third of distal phalanx (Wehbe-Schneider type 1/b, 2/a, 2/b, 3/a) joint were retrospectively analyzed. The DIP range of motion (ROM), Warren and Crawford scores, time to return to work/daily activity, operation time, the number of fluoroscopy shots, cost and complications were compared.

Results: No significant difference was found in the DIP ROM $(\mathrm{p}=0.708)$ and the Warren/Norris and Crawford scores $(\mathrm{p}=0.217$ and $\mathrm{p}=0.175$, respectively) between the two groups. Operation time and material cost were higher with HPT $(\mathrm{p}=0.006, \mathrm{p}=0.001)$. There was no significant difference in the number of fluoroscopy shots $(\mathrm{p}=0.344)$. Although DIP joint motion was started at two weeks in the HPT group and at eight weeks in the EBT group, no significant difference was observed in the time of return to work and normal daily life in both groups $(\mathrm{p}=0.859)$. Complications were observed in two patients in the EBT group and in three patients in the HPT group. No significant difference in total complications was observed between the two groups $(\mathrm{p}=0.666)$.

Conclusion: Bony mallet finger treatment with a custom-made hook plate prepared from 1.3-mm AO plates appeared to be clinically and radiologically similar to EBT. Additionally, HPT had the advantages of allowing early ROM to DIP joint and eliminating the need for a secondary surgery such as K-wire removal. On the other hand, hardware cost with HPT was higher than EBT.

Keywords: Bony mallet finger, distal interphalangeal joint luxation, hook plate, Ishiguro technique, Wehbe-Schneider classification. 
percutaneous pinning. ${ }^{[13,14]}$ and tension band ${ }^{[15]}$ are some of the methods used. In recent years, the EBT has gained popularity owing to its minimally invasive nature and its ability to achieve satisfactory postoperative results. ${ }^{[16-18]}$ However, multiple pin insertion attempts in EBT may cause DIP joint cartilage damage and arthrosis. ${ }^{[18]}$ Additional complications of EBT include iatrogenic terminal band rupture and extension lag, along with malunion, nail bed damage, and the development of superficial and deep infections. ${ }^{[18]}$ The main advantages of HPT include provision of anatomical reduction and stable fixation, avoiding the risk of fragmentation of the small dorsal fragment, allowing early movement and increasing patient comfort and compliance. ${ }^{[16,17]}$ Comparisons between techniques have previously been made; however, their obvious superiority to each other could not be shown. ${ }^{[18,19]}$

For the fixation of mallet fractures, both pre-made hook plates of various brands as well as methods describing custom hook plate preparation are available. ${ }^{[3,20,21]}$ However, these pre-made hook plates are impeded by high cost and lack of ease of availability. In this study, we, therefore, described a new technique for the preparation of mallet plate for use in the treatment of mallet fractures and compared the results with EBT. The presence of a longer hook to grab the fracture fragment is expected to provide more secure fixation and versatility in adapting to the shape and size of the fracture fragment.

\section{PATIENTS AND METHODS}

This single center, retrospective study was conducted at Metin Sabanci Baltalimani Bone Diseases Training and Research Hospital, Department of Hand Surgery between April 2015 and January 2018. The patients (13 males, 6 females; mean age: $30.9 \pm 9.2$ years; range, 17 to 48 years) who were diagnosed with mallet finger fractures, treated with EBT or HPT and followed for minimum six months were included. Patients with mallet finger fractures that occurred more than a month ago and those with loss of reduction independent of defects of the surgical technique (such as pin removal during dressing) were excluded from the study. A written informed consent was obtained from the patients and/or their legal guardians. The study protocol was approved by the Institutional Review Board of Metin Sabanc1 Baltalimani Bone Diseases Training and Research Hospital (No: 20.08.2020-61-433). The study was conducted in accordance with the principles of the Declaration of Helsinki.
A total of 12 patients were treated with EBT as described by Ishiguro et al., ${ }^{[22]}$ and 10 patients were treated with a custom-made hook plate that was contoured from a $1.3-\mathrm{mm}$ AO plate. Surgery is indicated for fractures involving one-third of the articular surface of the distal phalanx and volar subluxation of the distal phalanx. Demographic data of the patients, time until the operation and fracture types were recorded. Anteroposterior and lateral radiographs of the patients were taken preoperatively and at four and eight weeks after surgery. The time to return to work in employed patients and the time to return to daily life without restriction in unemployed patients were recorded. The patients were re-evaluated at six months postoperatively, and the Crawford ${ }^{[23]}$ and Warren/Norris ${ }^{[6]}$ gradings, DIP range of motion (ROM), extensor lag, nail problems and other relevant complications were recorded. During follow-up, the number of patients was reduced to nine in the HPT group and to 10 in the EBT group as the remaining patients failed to attend the follow-up appointment. Finally, a total of 19 patients including 10 who were treated with EBT (7 males, 3 females; mean age: $30.1 \pm 7.3$ years; range, 17 to 48 years) and nine who were treated with HPT (6 males, 3 females; mean age: $31.7 \pm 11.3$ years; range, 19 to 42 years) were enrolled.

\section{Surgical technique}

Extension block technique surgeries were performed under either infraclavicular nerve block or digital block. The injury was surgically intervened with an extensor block using the Ishiguro technique. ${ }^{[22]}$ Under fluoroscopy, the distal phalanx was extended to maximum flexion and a Kirschner wire (K-wire) was placed in the cephalic direction through the terminal band at an angle of 45 degrees to the mid-phalanx. Reduction of the fracture fragment was achieved by bringing the distal phalanx to extension. Subluxation of the DIP joint, if any, was corrected, and the DIP was transfixed with a second K-wire. A finger splint to fix the DIP joint was kept for three weeks and K-wires for eight weeks. Active movements were started, after the K-wires were removed.

\section{Hook plate method}

Plate preparation: Two holes in a $1.3-\mathrm{mm}$ standard AO plate were cut off from the body of the main plate. The second ring of this plate was cut at the far end and the ring was made two-legged. This ensured a longer leg length than previous plate preparation methods. These legs were extended to a 90-degree rotation from the connection point to the other ring and thus a hook plate was formed; previously, this 
was formed by bending the hook legs by 90 degrees. If necessary, adjustments could be made according to the size of the fragment by changing the rotation of the plate legs and the distance between each other (Figures 1 and 2).

Surgical technique: Infraclavicular nerve blockage or digital block was performed in all patients. An "H"-shaped incision was made on the DIP joint. The terminal band and fracture fragment were reached by ensuring preservation of the nail germinal matrix. The fracture fragment was reduced, and the DIP joint was transfixed with a provisional 1.2-mm K-wire. The legs of the plate were embedded in the terminal tendon to grasp the fragment. The plate was fixed to the distal phalanx with a $1.3-\mathrm{mm}$ screw and the K-wire was removed. Controlled passive motions were started at three weeks, while active movements were started at four weeks. Daily movements were allowed after six weeks.

\section{Statistical analysis}

Statistical analysis was performed using the NCSS (Number Cruncher Statistical System) 2007 Statistical Software (NCSS LLC, Kaysville, UT, USA).
Continuous variables were expressed in mean \pm standard deviation (SD) or median (min-max), while categorical variables were expressed in number and frequency. Normality distribution of the variables was done using the Shapiro-Wilk test. The Mann-Whitney $U$ test was used to compare independent continuous variables. The chi-square test was used to analyze the association between the categorical variables. A $p$ value of $<0.05$ was considered statistically significant.

\section{RESULTS}

In the HPT group, six patients were injured in their dominant side (six right, three left), while eight patients in the EBT group were injured in their dominant side (six right, four left). Ten patients described falling on their finger, five had their fingers caught in a fabric, and two suffered from injuries related to tools at their workplaces. Two patients were unaware of how the injury happened. Based on the Wehbe-Schneider classification, there were four $1 / b$, one $2 / \mathrm{a}$, one $2 / \mathrm{b}$ and three $3 / \mathrm{a}$ patients in the HPT group, while the EBT group had two $1 / \mathrm{b}$, two $2 / \mathrm{a}$, four 2/b and two 3/a patients (Figures 3 and 4 ).
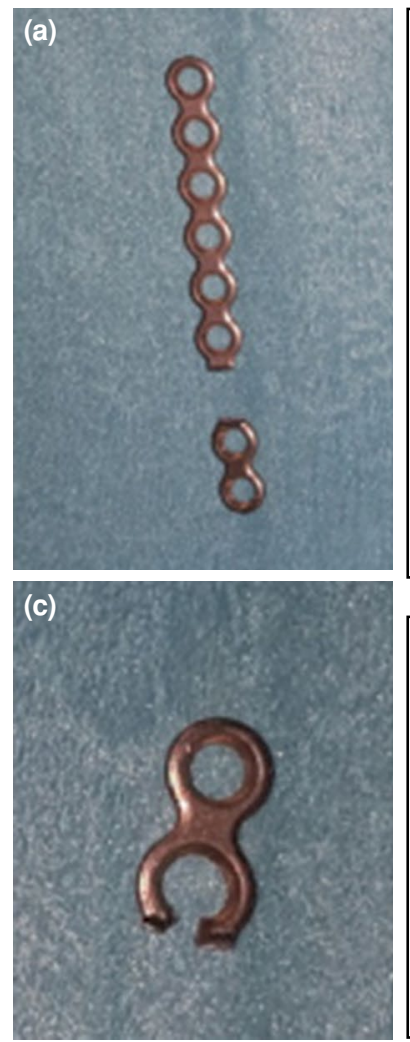
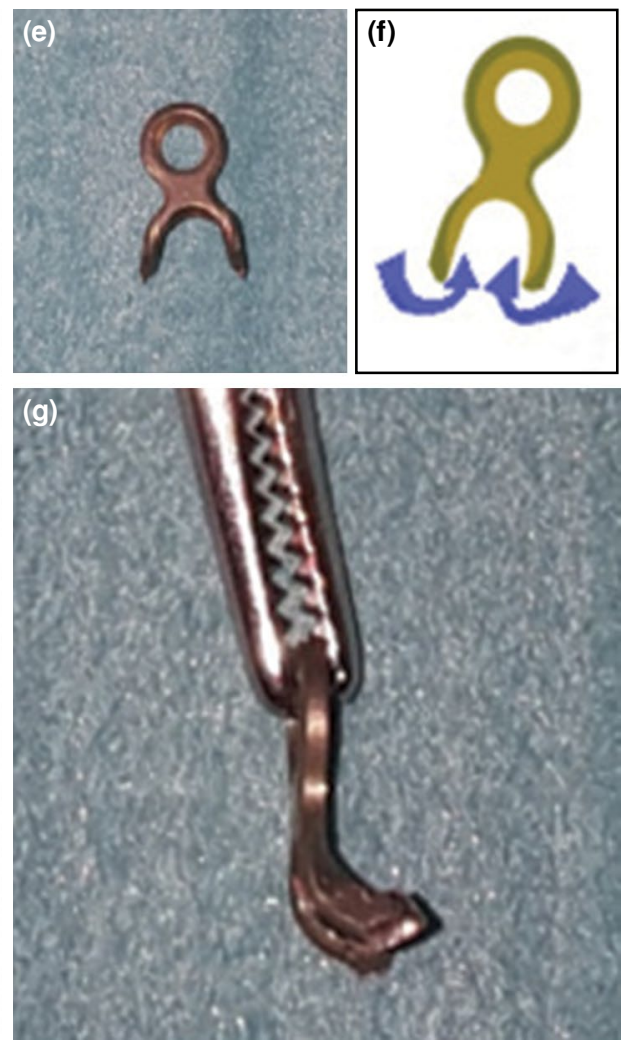

FIGURE 1. Plate preparation: (a, b) A two-hole part was cut from 1.3-mm AO plate. (c, d) One ring was cut from the far end and the ring was made into two legs. (e, f) Legs were rotated by 90 degrees. (g) Side view of the plate. 

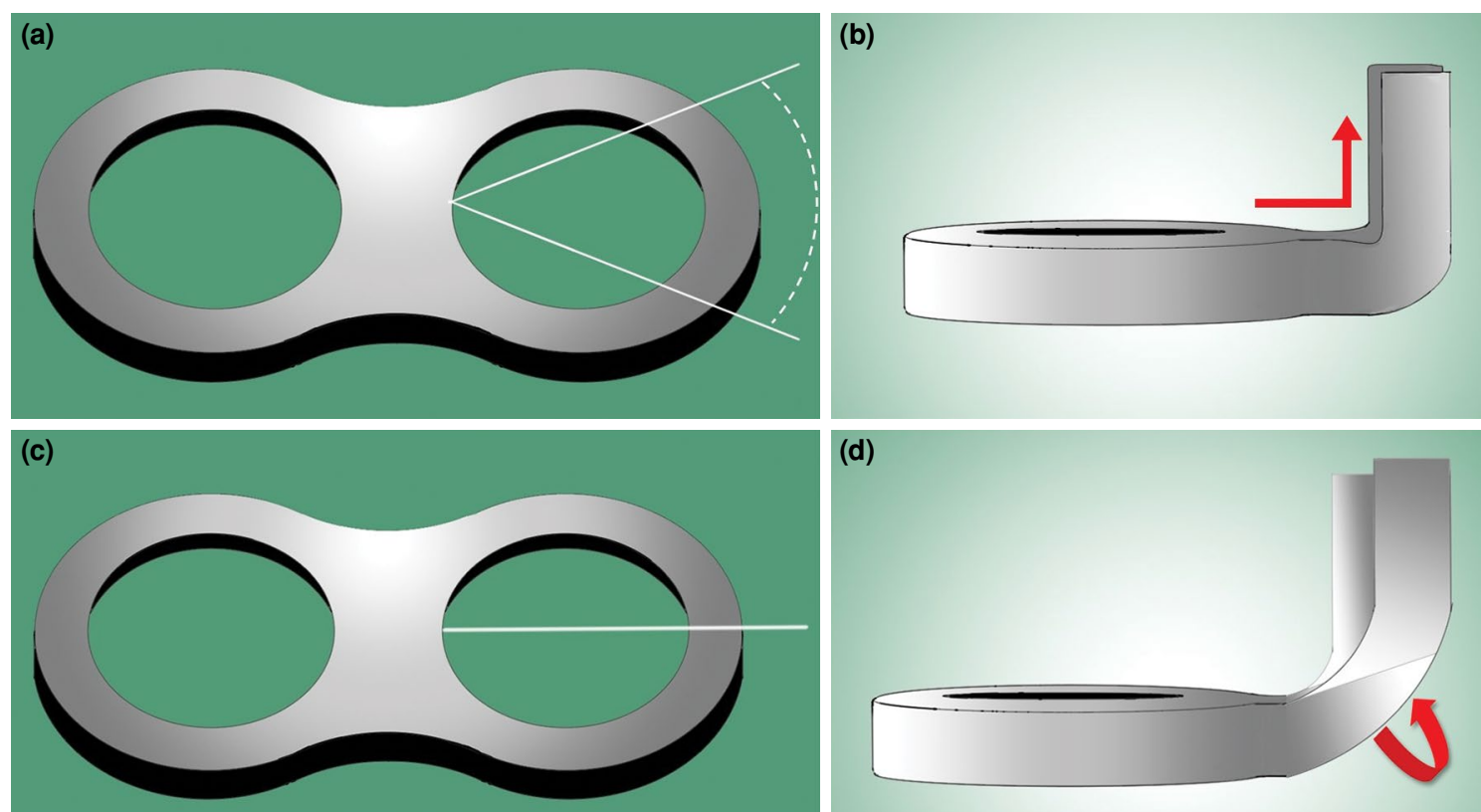

FIGURE 2. Differences between previously reported plate preparation methods and the new technique used in the current study: (a) Teoh's plate preparation technique: One third of the ring was resected. (b) Teoh's plate preparation technique: A hook was made by bending the legs by 90 degrees. (c) New plate preparation technique: Ring was cut at the far end. (d) New plate preparation technique: Hooks were made by rotating the legs by 90 degrees.

The mean surgery duration was $24 \pm 6.1 \mathrm{~min}$ in the EBT group and $38.3 \pm 11.7 \mathrm{~min}$ in the HPT group $(\mathrm{p}=0.006)$. The mean number of fluoroscopy shots during the operation was $18.3 \pm 11.5$ in the EBT group and 13.1 \pm 6.0 in the HPT group ( $\mathrm{p}=0.344)$. At the time of this study, the implant costs were TRY 7.4 ( US\$ 1) on average for EBT and TRY 780 ( US\$ 110) for HPT $(p<0.001)$. The duration of surgery and implant cost
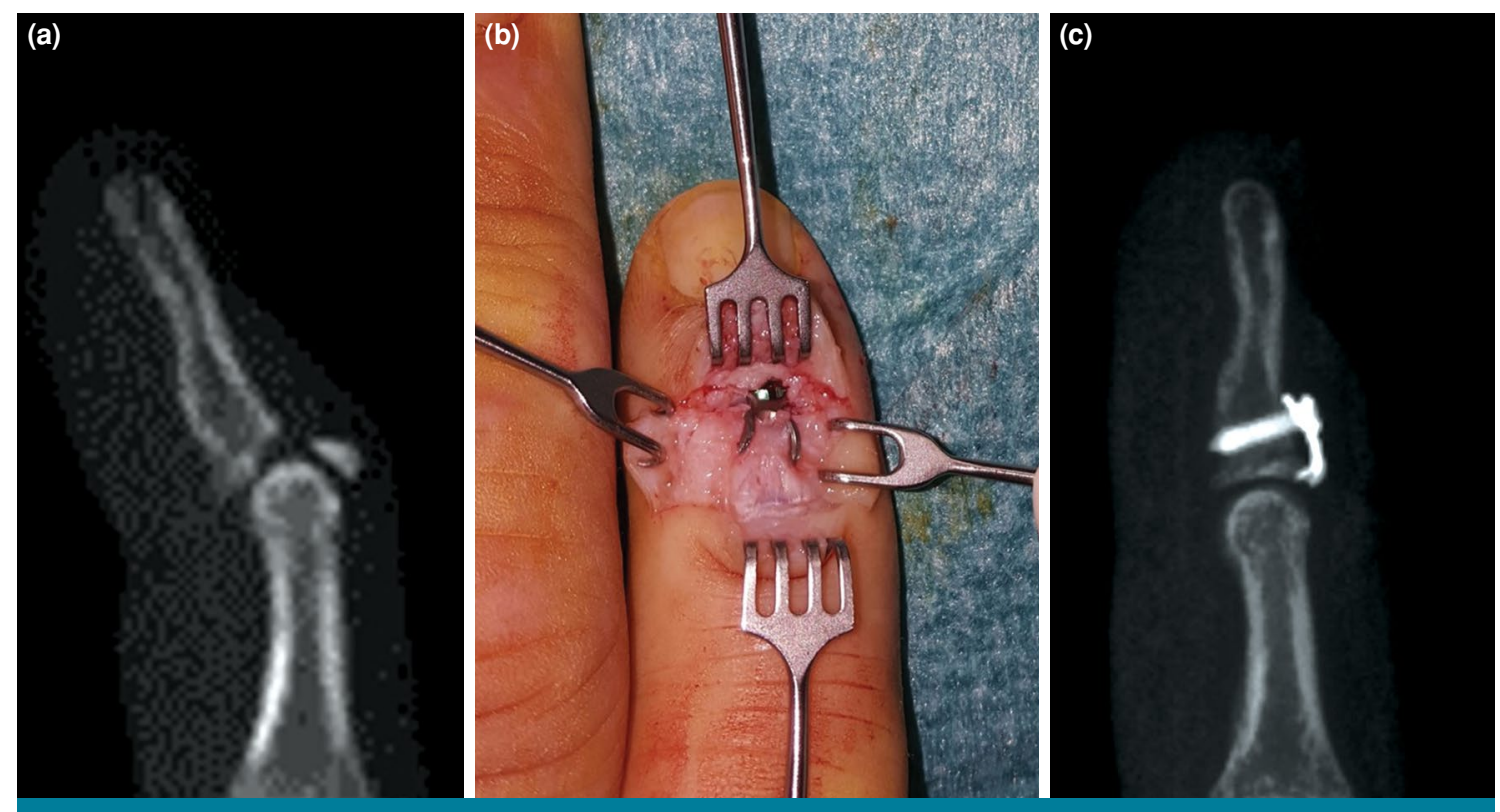

FIGURE 3. Preoperative and postoperative radiographies and intraoperative photographs of Patient 5 , showing the $5^{\text {th }}$ finger of the right hand of a 28 -year-old male patient. (a) Preoperative lateral radiography. (b) Intraoperative image. (c) Postoperative third-month radiography lateral image. 

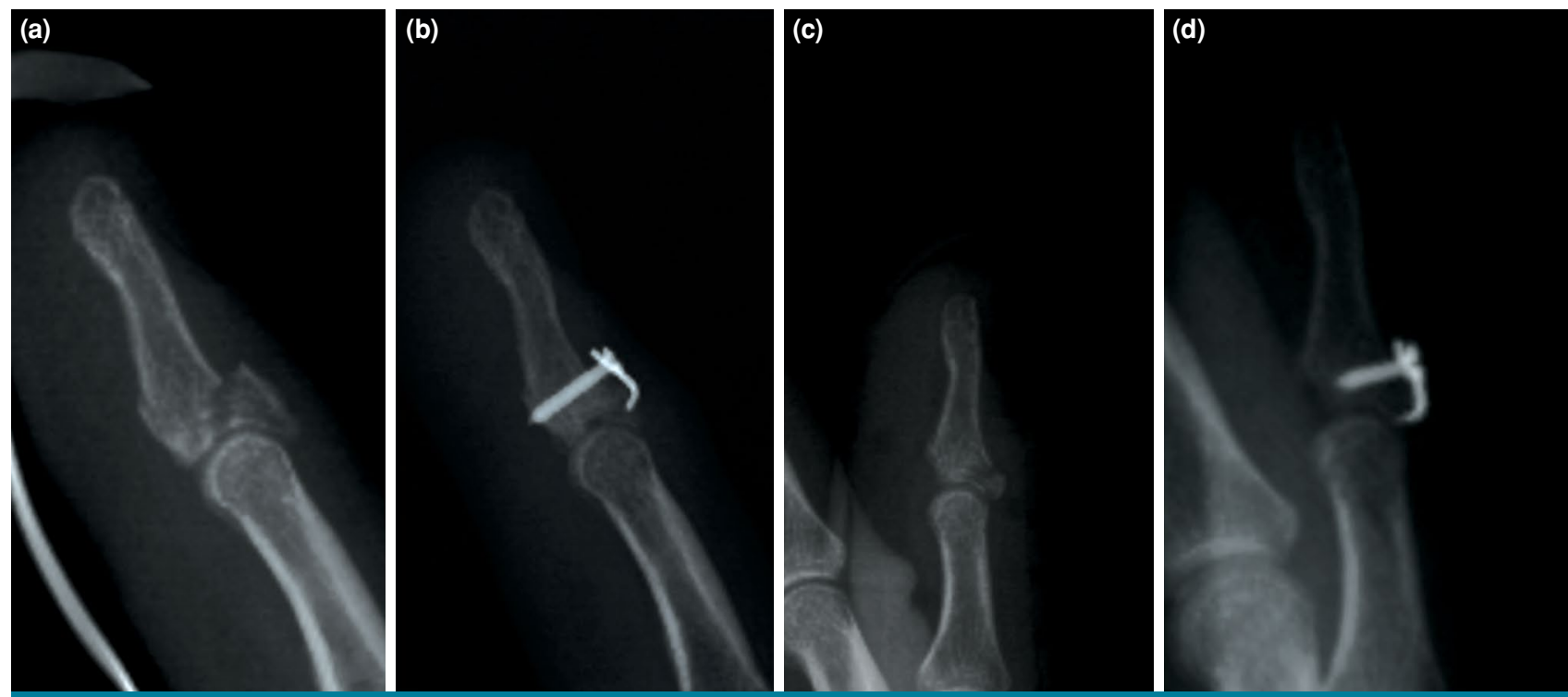

FIGURE 4. Preoperative and postoperative radiographies of patients with different fracture patterns. (a, b) Preoperative and postoperative lateral radiography of Patient 8 . (c, d) Preoperative and postoperative lateral radiography of Patient 9.

were statistically significantly lower in the EBT group.

Complications were observed in two patients in the EBT group and three patients in the HPT group $(\mathrm{p}=0.666)$. Among the patients who underwent EBT, one patient presented with a nail disorder and one patient had a loss of reduction. Among patients who underwent HPT, two patients presented with nail disorders and one patient had severe infection. In the latter patient, debridement and early plate removal

TABLE I

Crawford and Warren/Norris grades at the postoperative sixth month of follow-up and associated complications

\begin{tabular}{|c|c|c|c|c|}
\hline Patient no & Surgery & Crawford Score & Warren Score & Complications \\
\hline 1 & Plate fixation & Excellent & Success & Nail deformity \\
\hline 2 & Plate fixation & Excellent & Success & None \\
\hline 3 & Plate fixation & Fair & Failure & Deep infection \\
\hline 4 & Plate fixation & Good & Improved & Nail deformity \\
\hline 5 & Plate fixation & Good & Improved & None \\
\hline 6 & Plate fixation & Good & Success & None \\
\hline 7 & Plate fixation & Fair & Success & None \\
\hline 8 & Plate fixation & Excellent & Success & None \\
\hline 9 & Plate fixation & Good & Improved & None \\
\hline 10 & Extension block & Good & Improved & None \\
\hline 11 & Extension block & Good & Success & None \\
\hline 12 & Extension block & Good & Improved & None \\
\hline 13 & Extension block & Excellent & Success & None \\
\hline 14 & Extension block & Good & Improved & None \\
\hline 15 & Extension block & Good & Improved & Loss of reduction \\
\hline 16 & Extension block & Excellent & Success & None \\
\hline 17 & Extension block & Good & Improved & Nail deformity \\
\hline 18 & Extension block & Good & Improved & None \\
\hline 19 & Extension block & Good & Improved & None \\
\hline
\end{tabular}




\begin{tabular}{|c|c|c|c|c|}
\hline \multicolumn{5}{|c|}{$\begin{array}{l}\text { TABLE II } \\
\text { n of variables of patient groups }\end{array}$} \\
\hline & Groups & Count & Mean \pm SD & $p$ \\
\hline \multirow{2}{*}{ Age } & Plate fixation & 9 & $31.8 \pm 11.3$ & 0.712 \\
\hline & Extension block & 10 & $30.1 \pm 7.3$ & \\
\hline \multirow{2}{*}{ Time till surgery } & Plate fixation & 9 & $12.7 \pm 5.3$ & 0.487 \\
\hline & Extension block & 10 & $10.9 \pm 4.1$ & \\
\hline \multirow{2}{*}{ Time till start working } & Plate fixation & 9 & $9.6 \pm 1.7$ & 0.859 \\
\hline & Extension block & 10 & $9.6 \pm 1.3$ & \\
\hline \multirow{2}{*}{ Surgery time } & Plate fixation & 9 & $38.3 \pm 11.7$ & 0.006 \\
\hline & Extension block & 10 & $24.0 \pm 6.1$ & \\
\hline \multirow{2}{*}{ Number of fluoroscopy shots } & Plate fixation & 9 & $13.1 \pm 6.0$ & 0.344 \\
\hline & Extension block & 10 & $18.3 \pm 11.7$ & \\
\hline \multirow{2}{*}{ Implant cost } & Plate fixation & 9 & $780.0 \pm 0.0$ & $<0.001$ \\
\hline & Extension block & 10 & $7.4 \pm 1.4$ & \\
\hline \multirow{2}{*}{ Extension } & Plate fixation & 9 & $-4.4 \pm 3.9$ & 0.593 \\
\hline & Extension block & 10 & $-3.5 \pm 3.4$ & \\
\hline \multirow{2}{*}{ Flexion } & Plate fixation & 9 & $71.7 \pm 22.9$ & 0.670 \\
\hline & Extension block & 10 & $83.5 \pm 5.3$ & \\
\hline \multirow{2}{*}{ Total range of motion } & Plate fixation & 9 & $67.2 \pm 25.9$ & 0.708 \\
\hline & Extension block & 10 & $80.0 \pm 7.1$ & \\
\hline \multirow{2}{*}{ Complications } & Plate fixation & 9 & & 0.666 \\
\hline & Extension block & 10 & & \\
\hline \multirow{2}{*}{ Crawford score } & Plate fixation & 9 & & 0.175 \\
\hline & Extension block & 10 & & \\
\hline \multirow{2}{*}{ Warren score } & Plate fixation & 9 & & 0.217 \\
\hline & Extension block & 10 & & \\
\hline
\end{tabular}

were carried out and a temporary joint transfixation was performed with K-wires. Reoperation was recommended for the EBT patient who developed a loss of reduction; however, the patient refused the operation. Additional treatment was not recommended for patients with nail disorders. Crawford and Warren/Norris grades collected at the postoperative sixth month of follow-up and complications are shown in Table I. Comparison of age, time to surgery, time to work/daily activity, operation time, number of fluoroscopy shots during surgery, DIP joint extension, flexion, arc of motion, complications, and Crawford and Warren/Norris grades at six months after surgery is presented in Table II.

\section{DISCUSSION}

The current study showed that custom-made hook plates prepared from 1.3-mm AO plates yielded good clinical results in patients with bony mallet finger. ${ }^{[24]}$ We observed that the clinical data of the patients who underwent HPT were similar to the patients who underwent EBT, as well as to treatments applied with pre-made plates reported in the literature. ${ }^{[3,20]}$ We achieved good and excellent results in seven of nine patients undergoing HPT in the Crawford grade, which is one of the methods used to evaluate clinical results. In the Warren/Norris grade, which is another method that evaluates clinical results, successful and good results were obtained in eight of nine patients.

Mallet finger is primarily treated with splinting, regardless of whether it is fractured or tendinous. ${ }^{[16]}$ For bony mallet fingers, surgery is recommended, if the fracture fragment involves more than one-third of the joint and the distal phalanx is volar subluxated. ${ }^{[25]}$ The EBT is widely used, as it is simple and minimally invasive. ${ }^{[1,2,16,18,19]}$ In EBT, it is thought 
that prolonged immobilization of the DIP joint and damage to the cartilage of the joint by K-wires may lead to arthrosis and limitation of movement. ${ }^{[16,18,19]}$ In the current study, the average DIP joint motion arc at the postoperative sixth month in the patients treated with EBT was 80 degrees, which is consistent with the literature.

To alleviate the disadvantages of EBT, Teoh and Lee ${ }^{[3]}$ produced hook plates from 1.3-mm AO plates and applied them to nine patients. ${ }^{[3]}$ Union was achieved in all cases and the DIP ROM was measured as 64 degrees. Theivendran et al. ${ }^{[20]}$ reported successful outcomes in a patient treated with a similar technique. Following these studies, pre-made hook plates were produced by various commercial brands and utilized in clinics. Szalay et al. ${ }^{[11]}$ operated 59 patients with the Stryker brand hook plate and obtained very good and good outcomes. In the same study, problems in nail growth in seven patients and skin perforation by implant in two patients were reported. Vester et al. ${ }^{[26]}$ reported high patient satisfaction rates in patients treated with hook plates. Acar et al. ${ }^{[27]}$ retrospectively compared patients treated with pre-made hook plates with patients treated with EBT, and reported that although the use of HPT was technically more challenging, its stability was higher and allowed early mobilization and return to work. Moreover, we observed that the longer length of the hook in HPT enabled it to be adjusted easily only by rotating it according to fragment, thereby giving the surgeon more control over the fracture. On the other hand, Toker et al. ${ }^{[18]}$ reported similar outcomes with the use of pre-made HPT and EBT, highlighting that the plate was more costly. In the current study, we achieved a DIP ROM of 67 degrees in the HPT group. The average ROM reported in the literature for pre-made hook plates or other custom-made plates was 68.2 degrees. ${ }^{[3,11,18,20,27]}$ The DIP joint movements were allowed in the second week of HPT; however, time to return to work and daily activities was similar in HPT patients to the EBT patients. Corroborating the findings from Toker et al., ${ }^{[18]}$ we observed that material cost was significantly higher for the HPT in our study.

The most common complications of surgical treatments were described by Szalay et al. ${ }^{[1]}$ as nail growth and cosmetic problems in $12 \%$ patients. Acar et al. ${ }^{[27]}$ also reported nail deformities in three patients in the plate group and one patient in the K-wire group; removal of the implants was required in these patients. For open reduction and plate fixation, some authors recommend plate removal after three to six months to avoid nail deformities. ${ }^{[3,26]}$ In the current study, we also examined nail deformities in patients who underwent both HPT and EBT (Patient 17 undergoing EBT, Patients 1 and 4 undergoing HPT, Table I). We suggest that avoiding incorrect and multiple K-wire placement with EBT and avoiding placement of the plate close to the nail germinal matrix and meticulous protection of the matrix during the incision with HPT may prevent nail complications. Another complication of mallet finger surgery is the loss of reduction. ${ }^{[28]}$ This complication developed in one patient in the EBT group in our study (Patient 15, Table I). Since the patient rejected redo surgery, treatment was continued with splint and resulted in a 70-degree motion arc. Finally, one patient in the HPT group had wound infection, skin breakdown, and subsequent loss of reduction. In this patient, following material removal and debridement, the joint was transfixed with a K-wire. At the end of the treatment, a joint motion arc of 30 degrees was achieved (Patient 3, Table I).

Although patient selection for each surgical method was carried out randomly, the main limitation of the current study is its retrospective design. Another limitation is the small size of each patient group and relatively short follow-up. Nevertheless, these limitations may be overcome, as our data indicates successful clinical results of a new material design. Additionally, very few studies in the literature have directly compared EBT with HPT; all of these comparative studies have small sample sizes. ${ }^{[18,27,29]}$ A comparison of the longterm results of EBT with HPT would be a valuable contribution to the literature. Of note, all patients in the current study regained most of their functions at the end of the third month. Yet, another limitation of the current study is the lack of a comparison of custom-made plates with pre-made plates. However, one of our primary motivations in this study was the limited access to pre-made plates. We have described here a new HPT, which, to the best of our knowledge, is the first in the literature. In addition, the comparison of HPT with EBT for mallet fracture surgeries is a necessary contribution to the literature.

In conclusion, treatment of bony mallet finger with a custom-made hook plate is clinically and radiologically similar to the EBT with K-wire. However, with HPT, DIP joint motion can be started earlier and need for a second procedure such as removal of the K-wire can be discarded. Additionally, a custom-made HPT can be a good treatment option, if there is a particular need for the type of injury 
occurred, such as segmental fracture, since the plate has longer and more versatile hooks. Future studies comparing custom-made plates described in the current study with commercially available pre-made hooked plates in terms of cost and clinical and radiological success are warranted to draw more reliable conclusions on this subject.

\section{Declaration of conflicting interests}

The authors declared no conflicts of interest with respect to the authorship and/or publication of this article.

\section{Funding}

The authors received no financial support for the research and/or authorship of this article.

\section{REFERENCES}

1. Inoue G. Closed reduction of mallet fractures using extension-block Kirschner wire. J Orthop Trauma 1992;6:413-5.

2. Hofmeister EP, Mazurek MT, Shin AY, Bishop AT. Extension block pinning for large mallet fractures. J Hand Surg Am 2003;28:453-9.

3. Teoh LC, Lee JY. Mallet fractures: A novel approach to internal fixation using a hook plate. J Hand Surg Eur Vol 2007;32:24-30.

4. Okafor B, Mbubaegbu C, Munshi I, Williams DJ. Mallet deformity of the finger. Five-year follow-up of conservative treatment. J Bone Joint Surg [Br] 1997;79:544-7.

5. Stark HH, Gainor BJ, Ashworth CR, Zemel NP, Rickard TA. Operative treatment of intra-articular fractures of the dorsal aspect of the distal phalanx of digits. J Bone Joint Surg [Am] 1987;69:892-6.

6. Warren RA, Norris SH, Ferguson DG. Mallet finger: A trial of two splints. J Hand Surg Br 1988;13:151-3.

7. Chung DW, Lee JH. Anatomic reduction of mallet fractures using extension block and additional intrafocal pinning techniques. Clin Orthop Surg 2012;4:72-6.

8. Shimura H, Wakabayashi Y, Nimura A. A novel closed reduction with extension block and flexion block using Kirschner wires and microscrew fixation for mallet fractures. J Orthop Sci 2014;19:308-12.

9. Tetik C, Gudemez E. Modification of the extension block Kirschner wire technique for mallet fractures. Clin Orthop Relat Res 2002;(404):284-90.

10. Uzun M, Bulbul M, Ozturk K, Ayanoğlu S, Adanir O, Gürbüz $\mathrm{H}$. Surgical treatment of mallet fractures by extension block Kirschner wire technique surgical treatment of mallet fractures. Acta Ortop Bras 2012;20:297-9.

11. Szalay G, Schleicher I, Schiefer UR, Alt V, Schnettler R. Operative treatment of osseous pull out of the extensor tendon using a hook plate. Oper Orthop Traumatol 2011;23:151-7.

12. Kakinoki R, Ohta S, Noguchi T, Kaizawa Y, Itoh H,
Duncan SF, et al. A modified tension band wiring technique for treatment of the bony mallet finger. Hand Surg 2013;18:235-42.

13. Zhang W, Zhang $X$, Zhao G, Gao S, Yu Z. Pressing fixation of mallet finger fractures with the end of a K-wire (a new fixation technique for mallet fractures). Injury 2016;47:377-82.

14. Yamanaka K, Sasaki T. Treatment of mallet fractures using compression fixation pins. J Hand Surg Br 1999;24:358-60.

15. Damron TA, Engber WD. Surgical treatment of mallet finger fractures by tension band technique. Clin Orthop Relat Res 1994;(300):133-40.

16. Lin JS, Samora JB. Surgical and nonsurgical management of mallet finger: A systematic review. J Hand Surg Am 2018;43:146-63.e2.

17. Çapkın S, Buyuk AF, Sürücü S, Bakan OM, Atlihan D. Extension-block pinning to treat bony mallet finger: Is a transfixation pin necessary? Ulus Travma Acil Cerrahi Derg 2019;25:281-6.

18. Toker S, Türkmen F, Pekince O, Korucu İ, Karalezli N. Extension block pinning versus hook plate fixation for treatment of mallet fractures. J Hand Surg Am 2015;40:1591-6.

19. Lucchina S, Badia A, Dornean V, Fusetti C. Unstable mallet fractures: A comparison between three different techniques in a multicenter study. Chin J Traumatol 2010;13:195-200.

20. Theivendran K, Mahon A, Rajaratnam V. A novel hook plate fixation technique for the treatment of mallet fractures. Ann Plast Surg 2007;58:112-5.

21. Thirumalai A, Mikalef P, Jose RM. The versatile hook plate in avulsion fractures of the hand. Ann Plast Surg 2017;79:270-4.

22. Ishiguro T, Ito S, Uchinishi K, Yabe Y, Hashizume N. A new method of closed reduction for mallet fractures. Journal of Japanese Society for Surgery of the Hand 1988;5:444-7.

23. Crawford GP. The molded polythene splint for mallet finger deformities. J Hand Surg Am 1984;9:231-7.

24. Atik OŞ. What are the expectations of an editor from a scientific article? Jt Dis Relat Surg 2020;31:597-8.

25. Thillemann JK, Thillemann TM, Kristensen PK, FoldagerJensen AD, Munk B. Splinting versus extension-block pinning of bony mallet finger: A randomized clinical trial. J Hand Surg Eur Vol 2020;45:574-81.

26. Vester H, Schul L, von Matthey F, Beirer M, van Griensven M, Deiler S. Patient satisfaction after hook plate treatment of bony avulsion fracture of the distal phalanges. Eur J Med Res 2018;23:35.

27. Acar MA, Güzel Y, Güleç A, Uzer G, Elmadağ M. Clinical comparison of hook plate fixation versus extension block pinning for bony mallet finger: A retrospective comparison study. J Hand Surg Eur Vol 2015;40:832-9.

28. Tie J, Hsieh MKH, Tay SC. Outcome of hook plate fixation of mallet fractures. J Hand Surg Asian Pac Vol 2017;22:416-22.

29. Han HH, Cho HJ, Kim SY, Oh DY. Extension block and direct pinning methods for mallet fracture: A comparative study. Arch Plast Surg 2018;45:351-6. 